\title{
Оптовый рынок
}

\section{электроэнергии и мощности: возрождение регулирования? ${ }^{1}$}

Ю.А. ОРлОВА, кандидат экономических наук, Национальный исследовательский университет «Высшая школа экономики», Москва. E-mail: yorlova@hse.ru

Аннотация. Практика функционирования отдельных сегментов оптового рынка электроэнергии и мощности, созданного в рамках реформы электроэнергетики, показала эффективность рыночного подхода к формированию цен на основе конкуренции. Однако на рынке мощности в последние годы укореняются механизмы нерыночного характера: договоры о предоставлении мощности, обеспечивающие гарантированную норму доходности инвесторам и объем заказов отечественным предприятиям энергетического машиностроения, субсидирование тарифов отдельных регионов и т.п. Расширение применения элементов затратного подхода и использование энергорынка в качестве инструмента промышленной политики противоречат задачам реформирования и в долгосрочной перспективе несут риски для развития отрасли. А именно утрачивается канал передачи сигнала о реальных потребностях экономики, нарушаются стимулы производителей к повышению эффективности, создаются условия для проявления эффекта Аверча-Джонсона, тормозится технологический прогресс.

Ключевые слова: оптовый рынок электроэнергии и мощности; стимулирование инвестиций; договор о предоставлении мощности; распределенная генерация; затратный метод регулирования

JEL: L51, L52, L94.

Российская реформа электроэнергетики - один из немногих примеров последовательных и наиболее полно реализованных рыночных преобразований в новейшей истории страны. Она проходила в русле мировых тенденций и была призвана решить ключевую проблему недоинвестирования отрасли в период трансформационного кризиса 1990-х гг. и отсутствия у предприятий стимулов к снижению затрат в условиях регулирования тарифов. В этой связи одним из основных элементов проводимой реформы была адаптация рыночного ценообразования на потенциально конкурентных рынках производства и сбыта электроэнергии.

При этом на оптовом рынке электроэнергии мощность и электроэнергия рассматриваются как отдельные товары. Реализация

${ }^{1}$ Работа выполнена в рамках Программы фундаментальных исследований Национального исследовательского университета «Высшая школа экономики» в 2018 г. 
электроэнергии представляет собой ее физическую поставку потребителю, продажа мощности - обязательство выработки электроэнергии установленного качества в заранее оговоренном объёме. Как правило, в сегменте мощности договоры заключаются на несколько лет вперед. Основным преимуществом такой модели считается сглаживание колебаний цен на электроэнергию за счет того, что через механизмы рынка мощности происходит долгосрочное планирование спроса и предложения энергорынка, создавая ценовые сигналы для его участников, позволяя избегать дефицитов и адаптировать свои стратегии к возможным профицитам электроэнергии.

Становление рынка мощности в России не было простым: целевая модель рынка электроэнергии в России функционирует с 2011 г., но долгосрочные отборы на рынке мощности начались только в 2015 г. В ближайшем будущем должны закончиться текущие обязательства по договорам о предоставлении мощности (ДПМ), которые имели нерыночный характер и рассматривались как временная мера. Казалось бы, развитию рыночного ценообразования в отношении мощности ничто больше не должно мешать.

Но принятое решение о модернизации тепловой генерации на основе договоров с гарантированной нормой доходности вновь отодвигает этот вопрос на неопределенное время, поскольку этими договорами закрывается практически весь объем платежей, высвобождающийся в результате окончания договоров о предоставлении мощности. Таким образом, потенциально конкурентные сегменты на рынке мощности не расширяются, а временные механизмы, основанные на затратных подходах к ценообразованию, - закрепляются.

Цель данной статьи - оценить соответствие текущей модели оптового рынка электроэнергии и мощности (ОРЭМ) тем задачам, которые ставились в начале реформирования, и обосновать возможные краткосрочные и долгосрочные последствия решений по его развитию. Эта тема имеет большое практическое значение, поскольку перспективы развития энергорынка, а следовательно, и формирования конечной цены на электроэнергию, критичны для конкурентоспособности российской экономики. 


\section{Направления развития конкуренции в электроэнергетике: мировой опыт и концепция российской реформы}

Обобщая практику реформирования электроэнергетических систем мира и их академические исследования, можно выделить пять основных направлений, которые требуют выработки решений в ходе реформирования [Newbery, 1997; Jamasb, 2006].

1. Глубина разделения естественно-монопольных (диспетчеризация и передача электроэнергии) и потенциально конкурентных видов деятельности (производство и сбыт). В некоторых случаях проблема решается за счет разделения учета внутри единой компании с введением «китайских стен» между ее департаментами, иногда - путем разделения потребительских платежей по видам услуг (генерация, передача электроэнергии по магистральным и распределительным сетям, сбыт), наконец, - путем разделения компаний по видам деятельности с запретом на совмещение монопольных и потенциально конкурентных услуг в рамках одной группы лиц (российский вариант). Разделение собственников конкурентных и монопольных видов деятельности внутри отрасли призвано снять проблему нечестной конкуренции за счет перекладывания затрат с одного вида деятельности на другой и обеспечить недискриминационный доступ к сетям.

2. Разработка дизайна и внедрение механизмов ценообразования для потенциально конкурентных видов деятельности. При наличии нескольких производителей и поставщиков предпочтение, как правило, отдается рыночным механизмам формирования оптовых и розничных цен на электроэнергию, которые иногда, как в России, дополняются отдельным рынком мощности.

3. Разработка дизайна и внедрение системы тарифообразования для естественно-монопольных видов деятельности. В последние годы во многих странах мира затратные методы регулирования энерготарифов, главной целью которых является наиболее точная компенсация экономически обоснованных затрат монополиста, уступают место стимулирующим подходам, предполагающим использование более широкого спектра механизмов (предел роста цены, бенчмаркинг и др.) и мотивирующим компании к повышению операционной эффективности, поддержанию качества и надежности энергоснабжения, достаточного (но не избыточного!) уровня инвестиций. 
4. Приватизация энергетических активов. В большинстве стран, решивших приватизировать электроэнергетические активы, для привлечения в отрасль инвесторов в частную собственность передаются в первую очередь генерирующие и сбытовые компании, приватизация электросетевых мощностей происходит гораздо реже [Laffont, Tirole, 1993; Авдашева, Шаститко, 2015].

5. Формирование системы регулирования в отрасли. Многие исследователи [Guthrie, 2006] подчеркивают важность создания предсказуемых и работающих правил регулирования, механизмов разрешения споров, в первую очередь - относительно условий доступа к сетям естественных монополий.

В России реформа электроэнергетики шла в русле мировых тенденций и стала одним из самых заметных и законченных преобразований 2000-х гг. в стране. Важными ее элементами были создание конкурентных отношений там, где это возможно, и адаптация к местной специфике рыночных и стимулирующих методов ценообразования.

На сегодняшний день в отрасли завершено вертикальное разделение по видам деятельности, сформированы укрупненные компании в сфере производства, транспорта, передачи и сбыта электроэнергии; действуют оптовый и розничный рынки электроэнергии и мощности; разработаны новые правила тарифообразования для электросетевых компаний, целью которых было увеличение инвестиций в секторе и повышение операционной эффективности; приватизированы генерирующие и сбытовые компании.

Потенциально конкурентные секторы - оптовый и розничный рынки электроэнергии, рынок мощности - должны были продемонстрировать преимущества рыночного механизма ценообразования. Предполагалось, что складывающаяся в результате справедливой конкуренции цена сможет давать адекватные сигналы о движении спроса и предложения и в итоге послужит основой для инвестиционных решений.

Однако, по оценкам экспертов и отраслевых специалистов, говорить о возникновении конкурентных механизмов до недавнего времени можно было только в отношении оптового рынка электроэнергии. Вопросы низкой эффективности реформы исследуются в работах многих экспертов [Кутовой, 2017a, 2017b; Воротниций, Кузьмин, 2016; Колмогоров В.В., Митрофанов, 
2014; Электроэнергетика России..., 2014; Гительман, Ратников, 2013] и др.

В этой связи рассмотрим особенности организации российского оптового рынка и влияние последних решений регулятора на дальнейшие перспективы рыночных механизмов ценообразования.

\section{ОРЭМ: почти рынок}

На российском оптовом рынке электроэнергии и мощности принято разделять механизмы продажи электроэнергии и мощности. Рынок мощности, по замыслу, должен давать ценовые сигналы о средне- и долгосрочных потребностях потребителей в мощности; через него должна покрываться большая часть условно-постоянных затрат генерирующих компаний. Оптовый рынок электроэнергии удовлетворяет текущий спрос на электроэнергию, покрывая переменные затраты поставщиков.

ОРЭМ существует в двух ценовых зонах: первой (европейская часть России и Урал) и второй (Сибирь). В изолированных энергосистемах (Чукотский автономный округ, Камчатский край, Сахалинская и Магаданская области, Норильско-Таймырский $\mathrm{AO}$ и др.) и неценовых зонах, где реальная конкуренция среди производителей электроэнергии невозможна (Дальний Восток, Калининградская область и др.), тарифы устанавливаются регулятором².

Оптовый рынок электроэнергии представлен следующими сегментами.

1. Рынок на сутки вперед (РСВ). На него приходится около $70 \%$ объема реализации электроэнергии. Формирование цены происходит путем сбора заявок на планируемый объем покупки на следующие сутки, итоговая равновесная цена устанавливается на каждый час следующих суток на уровне наиболее дорогой принятой заявки. Такое ценообразование должно стимулировать производителей к снижению издержек и повышению за счет

\footnotetext{
${ }^{2}$ Объем и стоимость поставок электроэнергии в неценовых зонах формировали в 2017 г. около 4\% общероссийских; объем поставок мощности - 8\%, стоимость поставки мощности - 5\% (Годовой отчет АО «АTC» за 2017 год. URL: http:/www.atsenergo.ru/sites/ default/files/reportdocs/2018/05/ats_go.pdf). В изолированных энергосистемах в 2017 г. произведено около 1\% электроэнергии. URL: https://minenergo.gov.ru/node/532 (дата обращения: 20.10.2019).
} 
этого собственной маржи. Об эффективности такого подхода свидетельствует тот факт, что цены на РСВ растут гораздо медленнее, чем стоимость топлива ${ }^{3}$, которая составляет около $60 \%$ операционных затрат генераторов. Так, за период с 2007 по 2013 гг. в первой ценовой зоне (в топливном балансе преобладает газ) цена на газ для промышленных потребителей выросла примерно на 160\%, цена на электроэнергию на РСВ - на 90\%, в период 2013-2017 гг. газ подорожал на 30\%, а электроэнергия на $\mathrm{PCB}$ - на 9\% ${ }^{4}$. Для сравнения: накопленные темпы инфляции за 2013-2017 гг. составили 45\%.

2. Балансирующий рынок. В данном сегменте участники продают излишки или докупают недостающие объемы электроэнергии, которые образуются в результате неточного планирования на сутки вперед. Ценообразование определяется исключительно соотношением спроса и предложения. Таким путем реализуется до 6\% электроэнергии.

3. Рынок регулируемых договоров (РД) обеспечивает чуть менее $20 \%$ объема реализации электроэнергии. С 2011 г. РД заключаются только в отношении электроэнергии (и мощности), предназначенной для поставок населению, приравненным к населению группам потребителей, а также гарантирующим поставщикам, контролируемым межрегиональными распределительными сетевыми компаниями Северного Кавказа, Карелии, республик Тыва и Бурятия. Цены поставок определяются регулятором (ФАС РФ). Планировалось, что сегмент РД будет либерализован к 2015 г., сейчас от этого плана отказались.

4. Рынок свободных договоров (СД) подразумевает свободный выбор контрагентов и договорное определение цены и объемов поставки. Данный сегмент обеспечивает около 4\% объема реализации электроэнергии в России.

Работа оптового рынка мощности обеспечивается следующими механизмами.

1. Конкурентный отбор мощности (КОМ), по замыслу, должен был стать основным механизмом балансировки спроса и предложения мощности в энергосистеме, что предполагает

\footnotetext{
${ }^{3}$ Цена на рынке электроэнергии зависит также от состава загружаемого оборудования, сезонности, водности для ГЭС, графика ремонтов генераторов и сетей и т.п.

${ }^{4}$ Годовой отчет АО «ATC» за 2017 год. URL: http:/www.atsenergo.ru/sites/default/files/ reportdocs/2018/05/ats_go.pdf (дата обращения: 20.10.2018).
} 
долгосрочное планирование и формирование цены на несколько лет вперед. Однако если на оптовом рынке электроэнергии переходный этап закончился в 2011 г., то первый долгосрочный отбор мощности (на четыре года вперед) был проведен лишь в 2015 г. В 2017 и 2018 гг. на отборы мощности впервые наблюдалась конкуренция.

По замыслу, цена КОМ должна обеспечивать генераторам ресурсы для поддержания объема мощности, необходимого для удовлетворения спроса, т.е. покрывать как условно-постоянные затраты, так и капитальные вложения. Однако цены всех отборов, проведенных к настоящему моменту, ограничивались предельными значениями (и сверху, и снизу), определяемыми Правительством. Это вызывает недовольство представителей генерирующих компаний, поскольку для активной модернизации оборудования поступающих средств недостаточно.

2. Договоры о предоставлении мощности (ДПМ) впервые были введены в 2008-2010 гг. как механизм, обеспечивающий выполнение обязательств генерирующих компаний по вводу новых мощностей. В них прописаны количество, характеристики и сроки введения мощностей. Размеры капитальных затрат и условия оплаты мощности, поставляемой по ДПМ, определены Постановлением Правительства РФ № 238 от 13.04.2010. В частности, государство гарантирует участникам договоров определенную норму доходности ${ }^{6}$, а также обязуется обеспечить приоритет при покупке всей поставляемой по договорам мощности на протяжении 10 лет (при условии покрытия от 70\% до 95\% капитальных и эксплуатационных затрат). На практике это означает, что объекты, построенные по ДПМ, учитываются на рынке КОМ как приоритетные по отношению к действующей генерации.

Конкурентной борьбы за объекты ДПМ не было: они отбирались Системным оператором исходя из потребностей развития энергосистемы, основная задача генкомпании была - уложиться в предельные капзатраты.

В свое время механизм договора о предоставлении мощности принимался как вынужденное вмешательство в функционирование

\footnotetext{
${ }^{5}$ Последующие - определяли параметры поставки мощности на три года вперед.

${ }^{6}$ Привязка доходности по ДПМ к доходности государственных долговых бумаг приводит к колебаниям фактической доходности по годам в среднем от 13 до 17\%.
} 
рынка мощности - чтобы форсировать инвестиции в обновление генерирующих активов, зафиксировать инвестиционные обязательства новых собственников. Эти задачи удалось успешно решить: в рамках ДПМ было введено более половины новых мощностей в пореформенной электроэнергетике. Однако эффективность этого механизма послужила основанием для расширения его применения. В 2010 г. были введены ДПМ для объектов «РусГидро» (ГЭС) и «Росатома» (АЭС), включенных в Генеральную схему размещения объектов электроэнергетики. Мощность этих проектов также гарантированно отбирается на КОМ, оплачивается по методике Федеральной службы по тарифам (затратный метод) в течение 20 лет, исходя из окупаемости 25 лет.

Отметим, что средняя цена мощности по ДПМ на сегодня составляет около 870 тыс. руб./Мвт в месяц в первой ценовой зоне и 1040 тыс. руб./Мвт - во второй, что в 5,5 раза превышает цены на конкурентном отборе «старой» мощности [Модернизация.., 2017].

3. Рынок регулируемых договоров мощности (РДМ), цену на котором устанавливает ФАС РФ, так же, как и сегмент регулируемых договоров оптового рынка электроэнергии, обеспечивает потребности населения, покрывает около $30 \%$ всего объема поставок мощности ${ }^{7}$.

4. Рынок свободных договоров мощности (СДМ) предполагает заключение форвардных контрактов на поставку мощности (при условии, что она отобрана на КОМ). После снятия запрета на СДМ между зонами свободного перетока, действовавшего в 2011-2015 гг, объем поставок в этом сегменте начал быстро расти прежде всего в первой ценовой зоне, обеспечив около $30 \%$ поставок в 2017 г., во второй ценовой зоне сегмент СДМ составил около $10 \%$ в 2017 г. ${ }^{8}$

5. Мощность вынужденных генераторов. На данный момент на этот сегмент рынка приходится около 6\% генерации в РФ. Статус вынужденного генератора предоставляется энергоблокам или целым электростанциям, себестоимость выработки которых не позволяет им выйти на конкурентный отбор мощности, но из соображений надежности энергосистемы они не могут

${ }^{7}$ Годовой отчет АO «ATC» за 2017 год. URL: http://www.atsenergo.ru/sites/default/ files/reportdocs/2018/05/ats_go.pdf (дата обращения: 20.10.2018).

${ }^{8}$ Там же. 
быть остановлены. Цена мощности вынужденных генераторов оплачивается по тарифу, который формируется затратным методом и превышает цену КОМ.

\section{Рынка не будет?}

Анализ развития рынка мощности показывает, что использование механизма ДПМ с годами только разрастается, причем он становится не только способом привлечения инвестиций в электроэнергетику, но и инструментом развития смежных отраслей. Так, с 2013 г. в рамках стимулирования использования возобновляемых источников энергии (ВИЭ) и развития в РФ производства соответствующего оборудования проводятся конкурсные отборы инвестпроектов по строительству генерирующих объектов, функционирующих на основе ВИЭэ, важным условием которых является локализация производства оборудования. По результатам конкурсов заключаются договоры о предоставлении мощности на базе использования ВИЭ (ДПМ ВИЭ), которые гарантируют участнику проекта приоритет на российском оптовом рынке электроэнергии в течение 15 лет. Поставка мощности первого объекта, введенного в рамках ДПМ ВИЭ, началась в 2015 г.

В 2017 г. был проведен конкурсный отбор инвестпроектов по строительству генерирующих объектов, функционирующих на основе использования твердых бытовых отходов (ТБО) в Московской области (280 МВт) и Татарстане (55 МВт). Общая сумма инвестиций должна составить около 127 млрд руб. В качестве механизма возврата инвестиций снова используется ДПМ [Песчинский, 2018].

К расширению нерыночных механизмов формирования цены на оптовом рынке электроэнергии можно также отнести проблему вынужденной генерации, стоимость которой формирует около 4\% финальной цены на мощность. Динамика объемов вынужденной генерации в сравнении с объемами ввода и вывода мощностей представлена на рисунке. Как видим, проблема вынужденной генерации обострилась в 2015 г., когда по итогам конкурентного отбора мощности этот статус получили более 18 ГВт. Затем объемы вынужденной генерации начали снижаться, но вывод

\footnotetext{
${ }^{9}$ Постановление Правительства РФ № 449 от 28 мая 2013 года.
} 
мощностей, активизировавшийся было в 2016 г., в 2017-м опять затормозился.

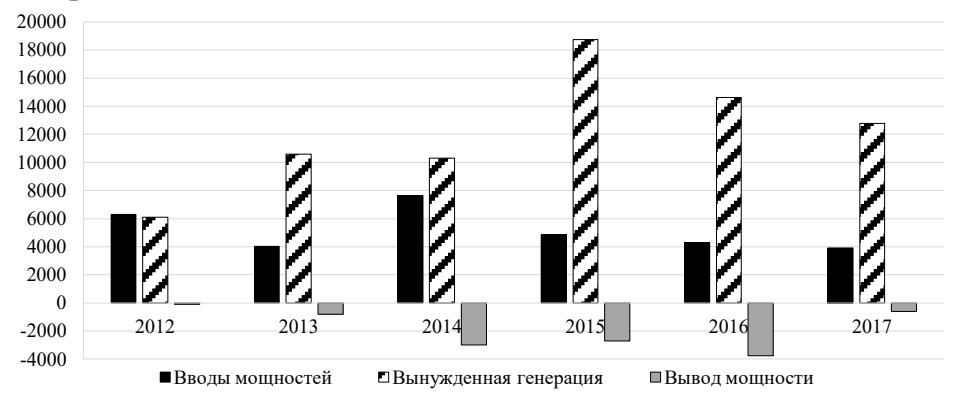

Источник: Минэнерго, $\mathrm{AO}$ «АТC».

Объемы вводов, выводов мощностей и вынужденной генерации в 2012-2017 гг., МВт

Довольно активно нерыночные механизмы регулирования применяются в изолированных энергосистемах, не входящих в ценовые зоны оптового рынка электроэнергии. Например, для пяти дальневосточных регионов, где энерготарифы значительно превышают среднероссийский уровень, на период 2017-2019 гг. установлена так называемая «дальневосточная надбавка», призванная выровнять цены. Механизм выравнивания действует следующим образом: генерирующие компании в Дальневосточном федеральном округе снижают свои тарифы до среднероссийского уровня, а на ОРЭМ устанавливается специальная надбавка к ценам продажи. Поступающие средства аккумулирует на своих счетах «РусГидро», которая затем перечисляет их в бюджеты дальневосточных регионов, а те компенсируют поставщикам энергии недополученную выручку ${ }^{10}$. По словам министра энергетики А. Новака, в 2017 г. финансирование этого механизма обошлось в 24 млрд руб., в 2018 г. - 34 млрд руб. ${ }^{11}$ Готовится предложение продлить действие «дальневосточной надбавки» еще на 10 лет.

\footnotetext{
${ }^{10}$ Как на деле выполняются нормы о выравнивании энерготарифов в ДФО. URL: https://www.eastrussia.ru/material/na-ravnenie-povattno-stanovis/ (дата обращения: 30.01.2019).

${ }^{11}$ Новак: регионы оплатят 40-45 млрд руб. за выровненные энерготарифы ДФО. URL: https:/ria.ru/teplo/20180910/1528198565.html (дата обращения: 20.10.2018).
} 
Основная масса нерыночных механизмов на ОРЭМ приходится на рынок мощности (таблица). Его доля в оптовой цене рынка электроэнергии и мощности постоянно увеличивается: по данным НП Совет рынка, в 2014 г. она составляла 30\%, в 2017 г. $-37 \%$, к 2023 г. может возрасти до 50\% ${ }^{12}$. Это означает, что и вклад нерыночных механизмов в цену ОРЭМ будет расти и рано или поздно превысит половину.

\section{Соотношение рыночных и нерыночных механизмов ценообразования на ОРЭМ для всех категорий потребителей в 2017 г., \%}

\begin{tabular}{|l|c|}
\hline \multicolumn{1}{|c|}{ Показатель } & $\begin{array}{c}\text { Доля сегмента в оптовой цене } \\
\text { на электроэнергию, }\end{array}$ \\
\hline Электроэнергетика & 51 \\
\hline Рынок на сутки вперед (РСВ) & 4 \\
\hline Балансирующий рынок (БР) & 6 \\
\hline Регулируемые договоры (РД) & 3 \\
\hline Финансирование неценовых зон & \\
\hline Мощность & 9 \\
\hline Конкурентный отбор мощности (КОМ) & 21 \\
\hline договорыопредоставлении мощности (ДПМ), в том числе: & 14 \\
\hline ДПМ ТЭС & 6 \\
\hline ДПМ АЭС/ГЭС & $<1$ \\
\hline ДПМ ВИЭ & 4 \\
\hline Регулируемые договоры (РД) & 2 \\
\hline Вынужденный режим & 1 \\
\hline Финансирование неценовых зон & 100 \\
\hline Цена ОРЭМ, в том числе: & 63 \\
\hline рыночные механизмы & 37 \\
\hline нерыночные механизмы & \\
\hline
\end{tabular}

Источник: расчеты автора.

Примечание: 1) курсивом выделены нерыночные механизмы; 2) свободные договоры не учитываются в цене ОРЭМ.

Что касается цены на мощность, здесь наибольшую долю занимает плата по ДПМ. Например, в первой ценовой зоне через ДПМ оплачивается всего около $17 \%$ мощности, но в стоимости мощности для потребителей, которые не относятся к населению и приравненным к ним категориям, доля ДПМ в 2018 г. составила

\footnotetext{
${ }^{12}$ Участники конференции «Новая Россия. Новая энергетика» обсудили перспективные направления электроэнергетики // URL: https://minenergo.gov.ru/node/9387 (дата обращения: 20.10.2018).
} 
почти $70 \%{ }^{13}$. Ожидать снижения вклада ДПМ в цену мощности (а с ним вместе и стоимости мощности) стоит не ранее 2021 г., когда начнут уменьшаться платежи по действующим контрактам (на данный момент по ним введено уже более $80 \%$ новых мощностей ТЭС). Казалось бы, по истечении срока последних ДПМ этот механизм должен совсем исчезнуть, а отрасль - вернуться к принципам ценообразования, заложенным в план ее реформы. Однако этого не случится, поскольку проблема старения инфраструктуры остается крайне острой, тепловая энергетика нуждается в модернизации, а КОМ не обеспечивает достаточного объема средств для инвестиций.

24 января 2019 г. Правительство РФ одобрило разработанную Минэнерго России программу модернизации теплоэлектростанций, подписано соответствующее Постановление № 43 от 25.01.2019 «О модернизации генерирующих объектов ТЭС»14. Программа рассчитана на 10 лет (с 2022 по 2031 гг.) и предполагает направление 1,9 трлн руб. (в ценах 2021 г.) потребительских платежей, высвобождающихся в результате окончания ДПМ, на проекты модернизации 41 ГВт тепловой мощности (около $16 \%$ всей установленной мощности российской электроэнергетики $)^{15}$. Все модернизационные проекты будут финансироваться по принципу ДПМ с фактической доходностью на уровне около $12 \%$, срок окупаемости - 15 лет $^{16}$. Постановление также определяет предельные относительные капитальные затраты для отбора инвестпроектов.

Масштабная модернизация должна простимулировать развитие отечественного машиностроения: в перечень обязательных условий ДПМ предлагается включить требование о локализации производства оборудования. Уровень локализации должен быть доведен до 90\%. Кроме того, предусмотрено предоставление льгот (например, отмена штрафов за срывы

\footnotetext{
13 Прогнозы свободных (нерегулируемых) цен на электрическую энергию (мощность) на 2018 г. по субъектам Российской Федерации на 2018 год и исходные данные для построения прогнозов на 28.09.2018. URL: https:/www.np-sr.ru/sites/ default/files/20180928_anpsr_ishodnye_dannye_i_prognoz_na_2018.pdf

${ }^{14}$ URL: http://static.government.ru/media/files/NKfJK1ZcqfJ $\bar{d} H J d G Q 5 q u C I T X 1 J M R$ eFAV.pdf

${ }^{15}$ Правительство Российской Федерации одобрило Программу модернизации ТЭС URL: https://minenergo.gov.ru/node/13784 (дата обращения: 04.02.2019).

${ }^{16}$ Новак: «Правительство одобрило программу модернизации ТЭС на 1,9 трлн рублей» URL: http://peretok.ru/news/strategy/19840/ (дата обращения: 04.02.2019).
} 
сроков ввода, аварии) компаниям, установившим турбины ряда производителей, по которым еще не налажен серийный выпуск.

На участии в программе использования средств, высвобождающихся после окончания ДПМ, настаивают также инвесторы ВИЭ, АЭС, цифровизации энергосетей.

Для финансирования модернизации энергомощностей на Дальнем Востоке (предварительно - 2ГВт, входят в 41 ГВт модернизируемой мощности, предварительная оценка требуемых инвестиций - около 200 млрд руб.) в первой и второй ценовых зонах предполагается ввести ещё одну спецнадбавку. Кроме того, обсуждается возможность привлечения к финансированию этих проектов и потребителей неценовых зон.

Итак, в числе основных тенденций развития ОРЭМ можно выделить:

- отказ от разделения с потребителями достигнутых эффектов модернизации генерирующих мощностей в форме снижения рыночной цены;

- распределение сэкономленных по итогам модернизации средств среди поставщиков рынка (даже при сохранении конкуренции между ними) с гарантированием уровня доходности инвестированного капитала;

- использование энергорынка в качестве инструмента стимулирования других отраслей экономики и отдельных регионов.

Таким образом, несмотря на все усилия по реформированию системы ценообразования в потенциально конкурентном секторе ОРЭМ, формирование ичен здесь все в большей степени основывается на затратных принципах, что в корне противоречит стратегии реформирования отрасли.

\section{Ожидаемые эффекты регуляторного вмешательства в ценообразование ОРЭМ}

В краткосрочной перспективе, на наш взгляд, эффекты от нерыночных механизмов ценообразования на ОРЭМ будут иметь смешанный характер. Так, например, ДПМ топливных электростанций вносят основной вклад в удорожание мощности для потребителей (кроме населения и приравненных к нему категорий), однако возникший благодаря применению этого механизма профицит в энергобалансе сдерживает и даже снижает цену на электроэнергию на рынке на сутки вперед. 
В то же время особенности графика оплаты по договорам о предоставлении мощности АЭС и ГЭС привели к резкому скачку цены на мощность в 2017 г., что вступает в противоречие с концепцией разделения рынков мощности и электроэнергии, согласно которой цены на мощность должны расти плавно, отражая долгосрочные тренды и смягчая пики на рынке электроэнергии, возникающие в период превышения спроса над предложением.

Инициативы, связанные с модернизацией теплоэнергетики, не должны существенно изменить ситуацию с ценами на электроэнергию, поскольку специально ставится задача недопущения роста цен выше темпов инфляции. Согласно анализу Vygon Consulting, среднегодовой прирост стоимости электроэнергии (включая мощность) с 2017 по 2030 гг. при реализации этой программы может составить до $3,7 \%$ при ее финансировании на основе механизма гарантирования доходности и от $3,2 \%$ - при расширении роли рыночных механизмов (либерализация цены КОМ). Долгосрочные эффекты предлагаемых изменений прогнозировать сложнее, но они могут оказаться весьма существенными для развития отрасли. Инициаторы и сторонники проводимых изменений мотивируют их соображениями как раз долгосрочных эффектов, в частности - необходимостью поддержания надежности энергосистемы. Действительно, большинство исследователей классифицируют обеспечение надежности энергоснабжения как общественное благо [Helm, 2013; Lagardea, Lantzc, 2018 и др.], достижение которого оправдывает вмешательство государства в деятельность отрасли.

Однако такое вмешательство в условиях рыночной экономики накладывает особую ответственность на регулятора, который должен балансировать между снижением инвестиционного риска и поддержкой рыночных сигналов (детально об этом см. [Steggals et al., 2011]). В российской ситуации, когда отрасль вплотную приближается к тому, что более 50\% цены ОРЭМ формируется нерыночными методами, риски потери или искажения рыночных сигналов критически возрастают.

Добавим, что сама ситуация, при которой ТЭС оказались не в состоянии самостоятельно заработать на модернизацию, возникла, по сути, в результате регуляторных решений. Так, например, их экономика сильно пострадала из-за навязанных регулятором принципов разнесения затрат на топливо между производством 
электроэнергии и тепла: в целях сдерживания тарифов на тепло для населения соответствующие затраты электростанций смещались на электрическую составляющую (при этом конкурентоспособность последней на ОРЭМ снижалась). И если задуматься, то трудно найти твердые основания считать, что в ходе модернизации теплогенерации регулятор, которому вменяется обеспечение не только надежности энергоснабжения, но и развития смежных отраслей и изолированных энергосистем, сдерживание тарифов для населения и т.п., окажется более эффективным.

Некоторые исследователи обращают внимание на то, что несмотря на нормативно зафиксированные ориентиры по капитальным затратам, гарантирование нормы доходности может привести к избыточности инвестиций [Averch, Johnson, 1962]. Данный эффект получил название эффекта Аверча-Джонсона, по имени описавших его исследователей. Предлагаемый для финансирования модернизации тепловых мощностей механизм имеет ряд отличий от тех ДПМ ТЭС, которые заключались в 2010 г. Так, претенденты на участие в программе будут конкурировать своими ценовыми заявками, кроме того, им не гарантируется приоритетный отбор мощности после завершения проекта, что делает всю схему более рискованной для них. Но и сами проекты модернизации гораздо более индивидуальны, чем новое строительство. Замены частей котлоагрегатов, турбинного оборудования, выключателей, золоотвалов и проч. - варианты комбинаций, в том числе неучтенных, бесчисленны. Асимметрия информации не позволяет заранее определить проекты, действительно востребованные потребителями, и их обоснованную стоимость. Использование же затратного метода формирования цены на мощность искажает стимулы производителей к повышению эффективности.

В складывающейся на энергорынке ситуации государство, помимо регулятивной, берет на себя еще и функцию визионера, определяющего стратегические направления развития отрасли. Многие страны уже второе десятилетие двигаются в направлении децентрализации энергопредложения, управления спросом и развития распределенной генерации ${ }^{17}$. Современные технологии

${ }^{17}$ Хотя распределенная генерация на основе ВИЭ развивается в основном также при активной поддержке государства, а издержки несут потребители. 
позволяют заметно снизить барьеры входа на рынок генерации. Например, небольшие газопоршневые станции, сопоставимые по эффективности с парогазовыми установками аналогичной мощности, возводятся в три раза быстрее последних (год вместо трех лет). Новые перспективы открывают и современные технологии хранения электроэнергии. Между тем те инициативы, что реализуются в российской электроэнергетике, продолжают принципы развития отрасли XX века: централизованное управление предложением, опора на крупные энергообъекты. На наш взгляд, российский вариант несет в себе больше рисков консервирования технологического отставания, чем западный.

\section{Заключение}

Создание оптового рынка электроэнергии и мощности большое достижение российской реформы электроэнергетики: ОРЭМ позволил внедрить конкурентные механизмы ценообразования в отрасли, которая долгое время была и считалась исключительно объектом регулирования. Однако если на рынке электроэнергии рыночные механизмы неплохо прижились, рынок мощности до сих пор является основным источником нерыночных компонентов в конечной цене ОРЭМ. Последние инициативы, связанные с программой модернизации тепловой энергетики, субсидированием смежных отраслей и региональных экономик через энергорынок, показывают, что затратные принципы отвоевывают себе все больше места в потенциально конкурентном секторе ОРЭМ. Переход к затратным методам ценообразования происходит в условиях приемлемых кратко- и среднесрочных эффектов: рост цены для конечных потребителей, скорее всего, не превысит инфляцию, хотя понесенные капитальные затраты могут оказаться избыточными из-за эффекта Аверча-Джонсона. Более серьезные риски, как представляется, возникают в долгосрочной перспективе. Они связаны с искажением стимулов в отрасли, риском потери рыночных сигналов об объеме и качестве спроса и предложения, а также с возможной задержкой технологического развития изза искусственного поддерживания модели функционирования электроэнергетики XX века. 


\section{Литература}

Авдашева С. Б., Шаститко А.Е. Нобелевская премия по экономике-2014: Жан Тироль // Вопросы экономики. 2015. № 1. С. 5-21.

Воротничий B. E., Кузьмин В.В. О повышении эффективности электроэнергетики на основе развития механизмов конкурентного электроэнергетического рынка // Энергетик. 2016. № 5. С. 3-10.

Гительман Л.Д., Ратников Б.Е. Уроки реформы в электроэнергетике: иллюзии, просчеты, перспективы // Вопросы экономики. 2013. № 12. С. 109-122.

Колмогоров В.В., Митрофанов Н. А. Реформа в электроэнергетике

состоялась, что дальше? // ЭКО. 2014. № 7. С. 78-102.

Кутовой Г.П. Продолжение реформ электроэнергетики России - совершенствование модели торговых отношений и ценообразования // Энергетик. 2017a. № 10. C. 21-24.

Кутовой Г.П. Электроэнергетика вновь перед выбором варианта дальнейших реформ // Энергетическая политика. 2017b. № 6. С. 22-34.

Модернизация ТЭС: маневр уклонения от рынка? // VYGON Consulting, ноябрь 2017. URL: https://vygon.consulting/upload/iblock/7f1/vygon_consulting power_plants_modernization.pdf

Песчинский И. Конкурс на строительство мусорных электростанций не подразумевал конкуренции// Ведомости. 22 июня 2018. URL: https:/ www.vedomosti.ru/business/articles/2017/06/22/695484-stroitelstvo-musornihelektrostantsii

Электроэнергетика России: проблемы выбора модели развития: аналитический доклад к XV Апрельской международной научной конференции по проблемам развития экономики и общества. Москва, 1-4 апреля/О.Г. Баркин, И.О. Волкова, И.С. Кожуховский и др. Нац. исслед. ун-т «Высшая школа экономики». М.: Изд. дом Высшей школы экономики, 2014. - 45 с.

Averch H., Johnson L.L. Behavior of the Firm Under Regulatory Constraint // American Economic Review. 1962. Vol. 52. No. 5. P. 1059-69.

Guthrie G. Regulating Infrastructure: The Impact on Risk and Investment // Journal of Economic Literature. 2006. Vol. 44. No. 4. P. 925-972.

Helm D. British infrastructure policy and the gradual return of the state// Oxford Review of Economic Policy. 2013. Vol. 29. No.2. P. 287-306.

Jamasb T. Between the State and Market: Electricity Sector Reform in Developing Countries // Utilities Policy. 2006. Vol. 14. P. 14-30.

Laffont J-J., Tirole J. A Theory of Incentives in Regulation and Procurement. Cambridge, MA: MIT Press, 1993.

Lagardea C.M., Lantzc F. How renewable production depresses electricity prices: Evidence from the German market// Energy Policy. 2018. Vol. 117. P. 263-277.

Newberry D. M. Privatisation and Liberalisation of Network Utilities // European Economic Review. 1997. Vol. 4. P. 357-383.

Steggals W., Gross R., Heptonstall P. Winds of change: How high wind penetrations will affect investment incentives in the GB electricity sector // Energy Policy. 2011. Vol. 39. P. 1389-1396. 
Для цитирования: Орлова Ю.А. Оптовый рынок электроэнергии и мощности: возрождение регулирования? // ЭКО. 2019. № 4. С. 113-131.

\section{Summary}

Orlova Yu.A., Candidate of Sciences (Economics), National Research University Higher School of Economics, Moscow

\section{Russian Wholesale Markets for Electricity and Capacity: Regulation Revival?}

Abstract. Power industry reform is one of a few transformations in Russian economy that was sophisticated by design and went far in its implementation. Electricity and capacity wholesale market (OREM) development started competitive pricing in a sector that had being considered as demanding regulation for a long time. The practice showed effectiveness of the market procedures at OREM. Nevertheless, non-market mechanisms at OREM are pervasive, namely capacity supply agreements that guarantee rate of return to generators and orders for national power engineering industry, subsidizing some regions, etc. Cost based price formation and using power market as an instrument of industrial policy contradict the aims of the reform plan and aggravate the long-term risks for the sector as well: the market loses pricing signals, the motivation for improving efficiency may be distorted, conditions for Averch-Johnson effect are provided, the technological progress is balked.

Keywords: wholesale market of electricity and capacity; incentives for investment; capacity supply agreement; distributed generation; cost based price formation

\section{References}

Avdasheva, S. B., Shastitko A.E. (2015). Nobel Prize in Economics-2014: Jean Tirole. Voprosy Ekonomiki. No. 1. Pp. 5-21. (In Russ.).

Vorotnitsky, V.E., Kuzmin, V.V. (2016). About Enhancing Efficiency in Power Industry Based on Competitiveness Mechanisms of Power Market. Energetik [Energy Man]. No.5. Pp. 3-10. (In Russ.).

Gitelman, L.D., Ratnikov, B.E. The Lessons of Power Industry Reform: Illusions, Errors, Perspetives. Voprosy Ekonomiki. No.12. Pp. 109-122. (In Russ.).

Kolmogorov, V.V., Mitrofanov N.A. (2014). Power Industry Reform Has Happened, What is Further? ECO. No. 7. Pp. 78-102. (In Russ.).

Kutovoy, G. P. Russian Power Industry Reform to Be Continued - Development of the Commercial Relations and Price Formation Model. Energetik No.10. Pp.21-24 (In Russ.).

Kutovoy, G. P. Power Industry Is in Face of Choosing Optiopn for Further Reforms. Energeticheskaya Politika. Energy Policy. No.6. Pp. 22-34. (In Russ.).

Heat power stations' modernization: a starting hole to escape the market? (2017). VYGON Consulting. 2017. Available at: https://vygon.consulting/upload/iblock/7f1/ vygon_consulting_power_plants_modernization.pdf (accessed 20.10.2018). (In Russ.).

Peschinskiy, I. (2018). The contest for the Rights to Build Waste-to-Energy Plants didn't Imply the Competition. Vedomosti. 22 June. Available at: https:// www.vedomosti.ru/business/articles/2017/06/22/695484-stroitelstvo-musornihelektrostantsii (accessed 20.10.2018). (In Russ.). 
Barkin, O., Volkova, I., Kozhukhovsky, I. et al. (2014). Russian Power Industry: The Choice Problems in Analytical Report for XV April International Academic Conference on Economic and Social Development. Moscow. 1-4 April. NRU Higher School of Economics. - Moscow, HSE Publ., 45 p. (In Rus.).

Averch, H., Johnson, L.L. (1962). Behavior of the Firm Under Regulatory Constraint. American Economic Review. Vol. 52. No. 5. Pp. 1059-1069.

Guthrie, G. (2006). Regulating Infrastructure: The Impact on Risk and Investment. Journal of Economic Literature. Vol. 44. No. 4. Pp. 925-972.

Helm, D. (2013). British infrastructure policy and the gradual return of the state. Oxford Review of Economic Policy. Vol. 29. No. 2. Pp. 287-306.

Jamasb, T. (2006). Between the State and Market: Electricity Sector Reform in Developing Countries. Utilities Policy. Vol. 14. Pp. 14-30.

Laffont, J-J., Tirole, J. (1993). A Theory of Incentives in Regulation and Procurement. Cambridge, MA: MIT Press.

Lagardea, C. M., Lantzc, F. (2018). How renewable production depresses electricity prices: Evidence from the German market. Energy Policy. Vol. 117. Pp. 263-277.

Newberry, D. M. (1997). Privatisation and Liberalisation of Network Utilities. European Economic Review. Vol. 4. Pp. 357-383.

Steggals, W., Gross, R., Heptonstall, P. (2011). Winds of change: How high wind penetrations will affect investment incentives in the GB electricity sector. Energy Policy. Vol. 39. Pp. 1389-1396.

For citation: Orlova, Yu.A. (2019). Russian Wholesale Markets for Electricity and capacity: Requlation Re vival? ECO. No. 4. Pp. 113-131. (In Russ.). 